\title{
Parques Urbanos de Curitiba (PR): Espacialidade, Planejamento e Turismo
}

\section{Urban Parks at Curitiba (PR, Brazil): Spatiality, Planning and Tourism}

\author{
Fabiana Calçada de Lamare Leite, Aline Patrícia Henz
}

RESUMO: As recentes transformações econômicas, sociais e culturais produzem modificações no planejamento das áreas urbanas, principalmente a disposição de espaços de lazer, também caracterizados como atrativos turísticos. Sendo a cidade um ambiente de encontro, trocas e realizações, associando sua diversificação e possibilidades de apropriação ao dinamismo, a urbanidade torna-se um atributo importante para o estabelecimento e manutenção do convívio social. Na lógica da atividade turística, a cidade é entendida como um produto que deve ter seus atributos desenvolvidos e direcionados à satisfação dos turistas. Para despertar o interesse do visitante, o planejamento local deve utilizar parâmetros de configuração dos instrumentos e equipamentos da cidade. A temática da atratividade associada à visitação, esta estritamente relacionada ao consumo do espaço. Consumo, que pode ser entendido como alvo de conhecimento, interesse em vivenciar determinado espaço com suas particularidades que o identificam, despertando a motivação em usufruir de suas singularidades. O objetivo central deste artigo é qualificar os principais parques urbanos de Curitiba apresentados como atrativos turísticos, no entendimento de que esta disposição espacial somada a oferta de serviços e infraestrutura potencializam sua atratividade para a atividade turística. De acordo com a Prefeitura Municipal, Curitiba dispõe de 17 parques urbanos (PMC, 2007), no entanto, esse trabalho limita-se a apresentar oito parques que estão inseridos no roteiro realizado pela Linha Turismo. A escolha desse universo justifica-se pelo fato de que essas localidades são atendidas pela Linha Turismo, um serviço turístico já consolidado na cidade que atende a diversos pontos, agregando atratividade e valor turístico por sua funcionalidade. A metodologia é de abordagem qualitativa e como técnicas, a pesquisa utilizouse de pesquisa bibliográfica e observação direta. Foi possível demonstrar que a lógica de organização da cidade, esta cada vez mais relacionada a lógica da atividade turística e que, é interesse de ambas a integração e a socialização de interesses. O planejamento da cidade ocorrendo de maneira articulada ao planejamento do turismo é a condição para a ocorrência de um turismo atrativo e competitivo para a localidade. Além disso, as duas práticas ocorrendo de maneira articulada podem beneficiar o desenvolvimento local, influenciando na qualidade de vida da população local e, consequentemente, beneficiando a atividade turística.

PALAVRAS-CHAVE: Turismo; Planejamento; Parques Urbanos; Curitiba/PR. 


\section{ABSTRACT}

Recent economical, social and cultural transformations are causing changes on the planning of urban areas, mainly those relative to the disposition of leisure spaces, also characterized as touristic attractions. As the city is an environment of encounter, exchange and fulfillments, with its diversity and appropriation possibilities being associated to dynamism, urbanism becomes an important asset for the establishment and maintenance of social cohabitation. Under the logics of touristic activity, cities are comprehended as a product that requires its attributes to be developed and directed towards the satisfaction of tourists. So as to stimulate the visitor's interest, local planning must apply configuration parameters of the city's instruments and equipment. The issue about attractiveness in relation to visits, is strictly linked to space consumption. Consumption can be understood as the aim for knowledge, the interest to enjoy certain space with the characteristics that make it particular, motivating towards the use of its singularities. The main objective of this article is to describe the main urban parks of Curitiba presented as tourist attractions, which are presented as touristic attractions, as it is considered that such a spatial disposition, added to a service and infrastructure offer, augment their attractiveness for touristic activities. According to the Municipal Mayor's office, Curitiba has seventeen (17) urban parks (PMC, 2016), however this research is limited to eight parks that are included in the itinerary deigned by the Linha Turismo. The selection of this universe is justified by the fact that they are places attended by the Linha Turismo, a consolidated touristic service in the city, which attends different spots, adding attractiveness and touristic value due to its functionality. It was possible to demonstrate that the city's configuration logic is increasingly related to touristic activity, and that both issues appreciate the integration and socialization of interests. City planning, when articulated to tourism planning, is the basic condition to accomplish a touristic attractiveness and competitiveness for such a place. Furthermore, when both practices are articulated in their evolution, they benefit local development, thus having an impact on the wealth of the local population, and also benefitting touristic activity.

KEYWORDS: Tourism; Planning; Urban Parks; Curitiba (PR, Brazil).

\section{Introdução}

Na produção e transformação do espaço, assim como na construção e consolidação da imagem de uma cidade, assumem um papel importante a transformação de um recurso turístico a partir de elementos espacialmente localizados, assim como, a dinâmica de visitação que os envolvem, como o caso de uma praça ou um parque acrescido de infraestrutura de apoio. É imprescindível compreender a espacialização dos elementos territoriais como fundamental na atividade turística, já que "o turismo tem no território sua principal matéria - prima”. (ANJOS, 2004, p. 154). Esta expressão pode ser entendida pelo fato do turismo ter no território o principal palco para expressar suas manifestações e experiências.

Kaick (2007) destaca que as recentes transformações econômicas, sociais e culturais produzem modificações no tratamento das áreas urbanas, principalmente sob a perspectiva de atrativo turístico, "isso ocorre também 
como decorrência de outras mudanças comportamentais que tem revigorado o uso de parques urbanos e de outras áreas verdes como opção de lazer pela população local e pelos turistas" (KAICK, 2007, p.13).

Nesse sentido, o turismo opera como atividade significativa na materialização dos elementos que configuram a mensagem mais atual na veiculação da imagem urbana, sendo resultado do ambiente físico e social (CIDADE; PELUSO, 1999). Por isso a necessidade de entender a cidade, suas características físicas, o relacionamento com quem a habita e, considerar essa relação nas ações de planejamento. Yázigi (2005) destaca que o espaço receptivo é importante em qualquer modalidade de turismo que se pratica, pois ele apresenta os componentes que geram o sentimento de atratividade ou o oposto a quem se pré-dispõe a conhecer um destino. Assim, "a cidade tem de existir para viabilizar nossos projetos de vida, do melhor modo possível” (YÁZIGI, 2005, p. 73).

Além disso, na medida em que a forma socialmente aceitável de resolver a sociedade com seu espaço, seja criativa, tem como produto, uma identidade própria, pelo menos espacialmente, isso ajuda a tornar alvo de interesse turístico. A cidade deve ser idealizada tanto para seus moradores quanto para quem a visita, proporcionando bem-estar e satisfação a todos.

$\mathrm{Na}$ lógica da atividade turística, a cidade é entendida como um produto que deve ter seus atributos desenvolvidos e direcionados à satisfação dos seus clientes, no caso, os turistas. Para despertar o interesse do visitante, o planejamento local deve utilizar parâmetros de configuração dos instrumentos e equipamentos da cidade.

Além das funções tradicionais (ecológica, ambiental, lazer e estética), as áreas verdes nos centros urbanos tanto públicas como privadas possuem uma propensão a serem ou se transformarem em atrativos turísticos. Os parques, bosques e jardins públicos de Curitiba são exemplos desta realidade, sendo estes os principais atrativos da Linha Turismo (URBS, 2016). De acordo com Beni (2004, p. 335), os jardins são equipamentos turísticos, que contam com "áreas destinadas ao lazer com tratamento paisagístico". Por isso, a visitação a estes espaços pode ser realizada tanto por moradores do entorno como por turistas.

Nesse sentido, o presente trabalho tem como objetivo qualificar os principais parques urbanos de Curitiba apresentados como atrativos turísticos, no entendimento de que a disposição espacial, somada à oferta de serviços e infraestrutura, potencializam sua atratividade para a atividade turística.

De acordo com a Prefeitura Municipal, Curitiba dispõe de 17 parques urbanos e (PMC, 2007), no entanto, esse trabalho limita-se a trabalhar com oito parques que estão inseridos no roteiro realizado pela Linha Turismo, a citar: Jardim Botânico; Parque Barigui; Parque Tingui / Memorial Ucraniano; Parque Tanguá; Parque São Lourenço; Bosque Alemão; Bosque do Papa / Memorial Polonês e Passeio Público. 
A escolha desse universo justifica-se pelo fato de que essas localidades são atendidas pela Linha Turismo, uma linha de transporte público considerada um serviço consolidado com itinerário planejado para atender diversos locais de interesse turístico na cidade, agregando atratividade e valor turístico por sua funcionalidade.

A pesquisa qualitativa foi a abordagem metodológica que caracteriza o presente trabalho. Esse tipo de pesquisa trabalha com interpretações, comparações e resultados que não podem ser mensuráveis numericamente, por isso Dencker (1998, p. 98), afirma que a pesquisa qualitativa "visa compreender ou interpretar processos de forma complexa e contextualizada e se caracteriza como um plano aberto e flexível'. Por não apresentar rigidez, a pesquisa qualitativa permite que o pesquisador proponha trabalhos com novos enfoques, como o caso da presente pesquisa.

Além disso, pesquisa qualitativa é pertinente ao presente trabalho por caracterizar-se pela maior intervenção dos participantes e ser menos controlável. O pesquisador participa e interpreta os fatos, usando análises consistentes e coerentes como argumentação para fundamentar suas ideias (MICHEL, 2005).

Para a realização da pesquisa, foram adotados como procedimentos metodológicos a pesquisa bibliográfica e a observação direta. Gil (2009) destaca que a pesquisa bibliográfica apresenta como principal vantagem a possibilidade de cobrir uma gama de fenômenos muito mais ampla do que se poderia pesquisar diretamente. E a observação direta consiste na coleta de dados não restringindo o pesquisador a apenas ouvir e ver determinadas realidades, ele também examina os fatos que deseja estudar (LAKATOS; MARCONI, 2010). Assim, a observação direta dos pesquisadores complementa as informações bibliográficas que fundamentam a pesquisa.

\section{Cidade e Turismo: espaço de atratividade}

Ao compreender a cidade em sua relação com o fenômeno turístico, é necessário interpretá-la como um produto turístico em oferta, identificando que elementos são responsáveis por configurar a cidade como atrativa em sua oferta como um produto turístico (WAINBERG, 2001).

De acordo com Sessa (1983), o produto turístico se realiza por meio de uma série de atividades e serviços relativos à hospedagem, à alimentação, aos transportes, à compra de produtos típicos aliados a visitas a atrativos naturais e locais de lazer e entretenimento. É esse conjunto de atividades, segundo o autor, que permite a construção do produto turístico final tornando os bens naturais e culturais diretamente produtivos. Essa participação direta dos bens de uma localidade na configuração do produto turístico participa do panorama econômico.

Em termos históricos, a atividade turística ganha forma de atividade econômica produtiva a partir do século $X X$, concomitante com os acontecimentos industriais. O turismo nas cidades ganha força, também, devido à crescente necessidade do cidadão de criar alternativas de 
relaxamento diante da pressão diária que sofre em seu cotidiano (CAVALCANTI; NEVES, 2016).

Além disso, é possível entender a atividade turística como uma troca, uma troca social na qual o turista é despertado a conhecer algo de seu interesse em troca, dentre outras razoes, de experiência pessoal, vivência e/ou conhecimento. E, quando essa troca é facilitada pela disposição espacial e ordenamento dos atrativos, a tendência é de que seja uma experiência positiva.

Camargo (2000) destaca que o desenvolvimento da infraestrutura baseada principalmente nos transportes, na comunicação e na organização e planejamento das cidades, foi elemento determinante para essa nova visão do turismo pela sociedade. Junto à isso, a diversificação da oferta turística em relação às tendências da demanda, ocasiona a expansão do mercado e o surgimento de distintos segmentos turísticos.

Assim, a segmentação para o turismo é a maneira de se entender as especificidades locais tanto concretas (infraestrutura, equipamentos, serviços), como abstratas (cultura, por exemplo) e assim, atuar de maneira responsável e aplicada a cada realidade.

Nesse momento estreita-se a relação entre a necessidade de entender a cidade, organizar e planejar seus espaços para que sua apresentação organizacional associada aos seus serviços e infraestrutura se torne tanto agradável ao seu morador como atrativa e funcional a quem a esta visitando. No caso dos parques urbanos de Curitiba, a infraestrutura instalada, transformou o entorno dos bairros, valorizando o ambiente aos que circulam pela cidade inserindo uma nova perspectiva de paisagem ao ambiente urbano (RIBEIRO; SILVEIRA, 2006).

Ao resultado dessa relação, podemos atribuir o que Reis (2001) chama de urbanidade. Conforme destaca o autor, a urbanidade pode ser entendida, também, como qualidade urbanística

que permite aos espaços públicos a sua apropriação pelos mais diferentes segmentos da sociedade, a partir de atributos físicos, sociais e culturais que possibilitam aos seus usuários, desfrutá-los com conforto, prazer e segurança (REIS, 2001, p. 3).

O mesmo autor diz ainda que "a qualidade do ambiente urbano se refere ao seu correto dimensionamento espacial, à infraestrutura e serviços oferecidos que permitem a sua utilização cotidiana plena e confortável" (REIS, 2001. p. 59).

Analogicamente, é possível afirmar que atributos da atratividade estão relacionados à urbanidade, não sendo excludente ou condicional. Essa afirmativa apenas demonstra como a forma, a organização da cidade e sua relação com quem convive com ela está relacionada à ocorrência da atividade turística. 
Sobre a urbanidade, há dois aspectos apontados pelo autor que devem ser relacionados: o primeiro, diz respeito à qualidade socioambiental do espaço urbano e abrange dois fatores interdependentes: conforto físicoespacial e o sentimento de afetividade proporcionado ao usuário. Isso representa o "significado histórico e simbólico que os espaços urbanos carregam, e que possibilita uma relação de identificação e afetividade com a sociedade ou com parte dela" (REIS, 2001, p. 59).

O segundo aspecto refere-se à cidadania, que

vinculada à participação e sustentabilidade social, estabelece a possibilidade de apropriação total e democrática dos espaços públicos pelos diferentes atores sociais, fomentando 0 aprimoramento das relações de convivência e de respeito pela diversidade cultural e morfológica - desenho urbano não repetitivo e monótono (REIS, 2001, p. 59)

Sendo a cidade um local de encontro, troca e realizações, associando sua diversificação e possibilidades de apropriação ao dinamismo, a urbanidade torna-se um atributo importante para o estabelecimento e manutenção do convívio social.

Entendemos, assim, que a urbanidade é um fator relevante para a atratividade de uma cidade. No contrário, a falta de urbanidade, pode refletir em espaços desconexos, fragmentados, arquitetonicamente estereotipados induzindo a uma apropriação social segmentada. (REIS, 2001). Mas, isso não significa afirmar que uma cidade só terá atratividade se tiver urbanidade.

A temática da atratividade associada à visitação, está estritamente relacionada ao consumo do espaço. Consumo, que pode ser entendido como alvo de conhecimento, interesse em vivenciar determinado espaço com suas particularidades que o identificam, despertando a motivação em usufruir de suas singularidades.

Em relação ao consumo do espaço, Moura (2007, p.344), diz que nesse processo "contribuem práticas de renovação urbana, de criação de ícones na paisagem construída, de oferta de serviços inusitados que sirvam tanto como atratividades quanto à valorização do solo e da cidade". Ainda, entre os produtos urbanos para uma sociedade de consumo, Moura (2007) destaca que a própria cidade se torna também produto, numa construção material e simbólica.

O turismo é uma atividade que produz e consome espaço, afirma ou seja, é "responsável pela sua produção e transformação, e toda a sua complexidade é expressa pelas relações sociais e pela materialização, que compõe o processo de produção desse espaço" (GANDARA et al, 2008, p.3).

Nesse caso, o "consumo" do espaço, sendo apropriado para a atividade turística está relacionado a atratividade despertada pela forma como a cidade apresenta organizado, planejado e estruturado os espaços 
destinados a esse fim. Os espaços quanto melhor organizado, planejado e estruturado tendem a serem mais atrativos e, consequentemente, mais "consumidos". No entanto, vale lembrar, conforme destaca Boullón (2002) que o espaço de produção e consumo, mesmo o de uso turístico, é dinâmico e sujeito à alterações diante os interesses e ações implantadas pelos atores sociais que o integram.

É a conversa que temos nesse trabalho sobre a espacialidade dos parques urbanos de Curitiba, organizados em forma de produto turístico pelo planejamento e oferta de um serviço que os torne mais fácil de serem "consumidos" e vivenciados, proporcionando uma maior interação e integração ao ambiente visitado.

\section{Espaços de lazer em áreas urbanas}

O espaço pode ser entendido como um produto social construído pela história e sua consequente evolução, caracterizado em diferentes aspectos pelos meios urbano e rural. Entende-se como espaço livre a área sem edificações, contudo, nem toda área livre pode ser considerada área verde, mas toda área verde constitui uma área livre. Lima et al. (1994) entende como área verde onde há vegetação arbórea, como praças, jardins públicos e parques urbanos.

Sobre o contexto histórico da organização do espaço, uma das respostas imediatas da industrialização foi o êxodo rural, impulsionando cada vez mais os indivíduos a buscar seu meio de sobrevivência no espaço urbano, alterando os hábitos sociais de produção e consumo. De acordo com Boullón et al. (2004, p. 77),

A concentração de pessoas no limitado território das cidades não é um fato casual; pelo contrário, ela deve ser qualificada como um fenômeno dinâmico que começa no período neolítico, com o advento da vida urbana, consolida-se na Idade Média, cresce no século 19 e acelera-se no século 20. Nesse período, [...] os homens iniciaram um movimento migratório, para as cidades, num deslocamento que na atualidade elevou a população urbana para $56 \%$ do total da população mundial.

O fenômeno da globalização, nos últimos 50 anos, alterou as relações sociais e seu entendimento no contexto da economia capitalista, resultando em mudanças na concepção do espaço (PORTUGUEZ, 2001). Tais mudanças, no cotidiano, nos hábitos e costumes da sociedade, alteram substancialmente 0 entendimento do espaço (principalmente urbano), refletindo em diversos aspectos, inclusive na qualidade de vida. Para Portuguez (2001, p.80), "o meio urbano [...] produz e reproduz modalidades de uso dos espaços, inclusive os destinados à recreação, a partir de perspectivas que eram inimagináveis até bem pouco tempo". Os desgastes físico, afetivo e emocional decorrentes dos desafios da vida urbana e da pressão no ambiente de trabalho, criam a necessidade da fuga, quando habitualmente se mostram eficazes as "áreas verdes", que proporcionam o 
contato com a natureza como alternativa para utilização do tempo livre. Rodrigues (2001, p. 126) explica que,

Grande parte dos paradigmas nos quais se baseiam as teorias da urbanização salientam que, conforme as populações sem concentram em espaços relativamente exíguos das cidades, desestruturam-se o processo produtivo e as relações sociais que caracterizavam a vida no campo. São substituídos por novas formas de divisão social e territorial do trabalho, nas esferas da produção, circulação, distribuição e consumo. Erigem-se novos valores, novas expectativas, outros estilos de vida.

Não somente o entendimento da necessidade do lazer mudou, mas a estrutura física para a prática do lazer também foi sendo alterada conforme o crescimento urbano e as novas dinâmicas sociais,

quando o desenvolvimento industrial começou a atingir as cidades, não havia distinção entre áreas habitacionais, áreas de lazer e áreas industriais, [...], isto é, à medida que as pessoas vão chegando, em busca de trabalho nas indústrias, instalam-se próximo a elas (BACAL, 2003, p. 76).

Atualmente várias cidades brasileiras, principalmente aquelas em vistas ao crescimento industrial, já não possuem "espaços livres" para práticas de atividades cotidianas de lazer, e até mesmo nos bairros residenciais está aumentando a tendência à verticalização, diminuindo os espaços públicos para a prática do lazer. O rápido e desordenado crescimento urbano e a falta de políticas eficazes para seu ordenamento, muitas vezes tornam estas cidades ambientalmente inadequadas para a ocupação humana, tanto pela concentração populacional quanto pela falta de espaços livres. Uma das alternativas para coordenar a distribuição do espaço das cidades é o planejamento paisagístico, que deve satisfazer as funções ecológicas, sociais (lazer) e estéticas, preocupando-se com a acessibilidade, controle e monitoramento das áreas verdes urbanas (PORTUGUEZ, 2001).

A preservação da paisagem urbana, além de servir como um atrativo turístico (relacionado à imagem do espaço) também estabelece um padrão de qualidade de vida, a partir da disposição estética dos espaços livres inseridos no contexto urbano destinados para prática de lazer da população. É necessário compreender que a paisagem significa muito mais do que somente a percepção da natureza, mas demonstra também os aspectos culturais, éticos e morais que são concebidos na vida social cotidiana. Silva (2004, p.21) afirma que a

paisagem urbana 'bem composta', [...] de construções bem conservadas, de ruas arborizadas, de praças e generosos jardins, é um exemplo de uma das idealizações de cidade que frequentemente são utilizadas para influenciar o turista. 
Assim como os moradores normalmente conseguem identificar as relações econômicas do seu entorno, a paisagem urbana deve estar organizada de tal maneira que o morador também visualize as demais dinâmicas deste espaço, compreendendo a formação das áreas comerciais, industriais, residenciais e de lazer. O desafio atual no planejamento das cidades é administrar a paisagem urbana apresentando um aspecto geral harmonioso de espaços pitorescos, voltado às necessidades locais. Silva confirma que (2004, p.31), "o que para o turista é uma experiência essencialmente estética, para o nativo é uma avaliação do próprio modo de vida".

$\mathrm{Na}$ atual conjuntura da sociedade pós-moderna, o sentido e as vivências cotidianas, são mais importantes do que a quantidade, traduzindo a lógica do uso do lazer como instrumento de melhoria da qualidade de vida da comunidade, construindo uma identidade para as cidades. A experiência estética vivenciada pelo turista deve ser considerada, contudo, a preservação da imagem de uma cidade socialmente organizada deve estar focada na vivência dos moradores,

\begin{abstract}
A imagem da cidade que seus habitantes e visitantes constroem mentalmente depende de experiências individuais de percepção e visualização do ambiente construído. O percurso pela cidade é um fator determinante na montagem de um quadro mental. Os caminhos por onde passam turistas ou moradores periodicamente compõem o seu repertório visual e seu aspecto é extremamente importante para a construção da imagem da cidade (SILVA, 2004, p. 180).
\end{abstract}

Transformar e propor alternativas para a organização do espaço urbano e desenvolvimento social é uma função governamental, idealizada por meio de políticas públicas, que nem sempre assumem sua parcela de responsabilidade na construção de valores sociais, segundo Marcellino (1983, p.31),

As resistências aos valores do lazer observadas na moral
tradicional são ainda mais enfatizadas quando se analisa o
fenômeno em termos da realidade brasileira, tendo em vista
nossa condição de subdesenvolvimento. Dessa forma,
políticas efetivas nessa área são obstaculizadas pelas
barreiras impostas ao lazer na ideologia do
desenvolvimento.

Em síntese, a utilização sustentável dos espaços em áreas verdes para a prática do lazer, além de valorizar o espaço urbano, contribui para aumentar a qualidade de vida da população, uma vez que o lazer está inserido como um direito social do cidadão brasileiro. Com o entendimento de que há necessidade de estruturas físicas para a prática do lazer, destacam-se como benefícios: 
-Apresentação estética favorável para o incentivo ao turismo e também como critério para melhorar a qualidade de vida da população;

-Valorização da paisagem urbana, que influencia diretamente nos aspectos econômicos, como a valorização imobiliária;

- Oferta de entretenimento e incentivo para a prática do lazer (e esportes em alguns espaços) para todas as faixas etárias;

-Aumento da segurança nos espaços abertos, visando a diminuição da criminalidade e dos pontos de venda e uso de drogas no município.

A partir da compreensão das dinâmicas do uso dos espaços de lazer, a conservação destas áreas pode agregar valor a cada um aos aspectos social, cultural, econômico e ambiental que, juntos, compõem o desenvolvimento sustentável, conforme segue:

-Aspecto social: as práticas lúdicas contribuem para interação da população, de todas as classes sociais, promovendo a sociabilização e o respeito das vivências, incluindo portadores de necessidades especiais;

-Aspecto cultural: a correta utilização dos espaços de lazer e sua manutenção devem conservar a história local e, as atividades de recreação em tais espaços, podem servir como um meio de informação sobre a formação cultural do município;

-Aspecto econômico: os espaços verdes em áreas urbanas são entendidos, atualmente, como um fator primordial para valorização da paisagem, que reflete diretamente nos negócios imobiliários, tanto residenciais quanto comerciais. A imagem construída será também determinante para a atratividade e tipologia de investimentos;

-Aspecto ambiental: com a preservação dos espaços verdes é proporcional a preservação da fauna e da flora e, a proximidade do homem com a natureza (no caso dos moradores nos espaços de lazer) é uma das alternativas para educação ambiental.

\section{Planejamento Urbano e Turismo}

Planejar, segundo Molina (1997), implica em identificar variáveis para adotar um curso de ação, com análises que permitam alcançar uma situação pré-determinada com o objetivo de organizar e melhorar a vida dos cidadãos de uma localidade. Ferrari Junior (2004) diz que o planejamento tem como finalidade a organização de meios a serem utilizados para atingir uma meta que contribuirá para a melhoria de uma determinada situação.

Nesse sentido, aplicar a técnica do planejamento ao território urbano proporciona: organização espacial, social e ambiental a partir da 
necessidade de cada local e sua dinamicidade (RIBEIRO; SILVEIRA, 2006). Como consequência, organiza o espaço para o turismo potencializando sua atratividade. Assim,

o planejamento deve considerar não só o estabelecimento de uma ordem de ação que conduz a uma situação desejada que assegura, por meio do processo racional e metodológico, a organização do espaço urbano. Os planejadores devem preocupar-se com as pessoas e as formas de ocupação desse espaço urbano (RIBEIRO; SILVEIRA, 2006, p.311).

O planejamento deve considerar além do prático e racional para ser executado. Os atores envolvidos devem ser ouvidos e considerados para assim, qualquer ação de planejamento ser harmônica com o ambiente e com as pessoas que com ele convivem.

Curitiba, desde sua fundação, passou por diversos planos diretores e alterações urbanas que tinha como objetivo, soluções para problemas da cidade e a busca por melhorar a qualidade de vida do morador da cidade (GANDARA et al, 2008).

A presença cada vez mais intensa da atividade turística como elemento fundamental ao entendimento e planejamento da cidade, tem feito emergir estudos em que ambas as finalidades de planejamento sejam trabalhadas em conjunto. Costa (2001) aborda o tema do planejamento do turismo em paralelo ao planejamento da cidade, entendendo que a atividade de planejar o espaço para o turismo está relacionada ao planejamento da cidade no que se refere às atuações e configurações urbanas, assim como, ao modo de vida e de pensar que se reflete nas novas formas de atuar sobre o espaço e seus agentes condicionantes.

É possível entendermos tal ideia, pois Costa (2001) justifica suas afirmações apontando a proximidade entre o planejamento da cidade e 0 planejamento do turismo como uma razão para o planejamento do turismo estar emergindo como uma especialização do planejamento da cidade em função de necessidades e desejos dos residentes, forças do mercado e a posição do local no mercado mundial.

A aproximação do turismo ao planejamento da cidade reforça a tendência cada vez maior de interação entre distintos locais, a troca de costumes, a relativização de distâncias e 0 sentimento de multipertencimento que a sociedade tende a apresentar. Isso porque, as viagens despertam curiosidades, nos levam a viver experiências não rotineiras, a conhecer e nos submeter a hábitos que não teríamos em nosso local de morada.

Além disso, o espaço da cidade quando bem planejado e, consequentemente executado, faz com que os espaços construídos, preservados e revitalizados contribuam de maneira significativa para uma vivência mais rica da cidade (MARCELLINO, 2000). Isso, de certa forma, contribui para a atratividade de um destino turístico. O autor reforça 
afirmando que "preservando a identidade dos locais, pode-se manter, e até mesmo aumentar o seu potencial turístico" (MARCELLINO, 2000, p.28).

No caso especifico de Curitiba, Gandara (2008) destaca que o impacto das ações urbanas como as soluções de transporte coletivo que atrai grupos específicos de técnicos e estudantes, contribui para o aumento da demanda turística.

Em outro exemplo, a Linha Turismo é um exemplo de planejamento da cidade associado ao planejamento da atividade turística. O presente trabalho adotou esse serviço de transporte público para demonstrar a funcionalidade e importância da relação entre o planejamento da cidade e o planejamento do turismo tomando como a questão cultural como segmento de análise.

\section{A Linha Turismo em Curitiba/PR}

A Linha Turismo foi implantada em 1999 pela Prefeitura Municipal de Curitiba em parceria com a URBS (Urbanização de Curitiba S/A). Esse serviço percorre uma extensão de aproximadamente $45 \mathrm{~km}$ composto por 25 atrativos divididos em 8 conjuntos de parques ou bosques, além de teatros, praças, museus, monumentos, universidades, edifícios históricos, construções de referência para a cidade, entre outros atrativos (Figura 1)

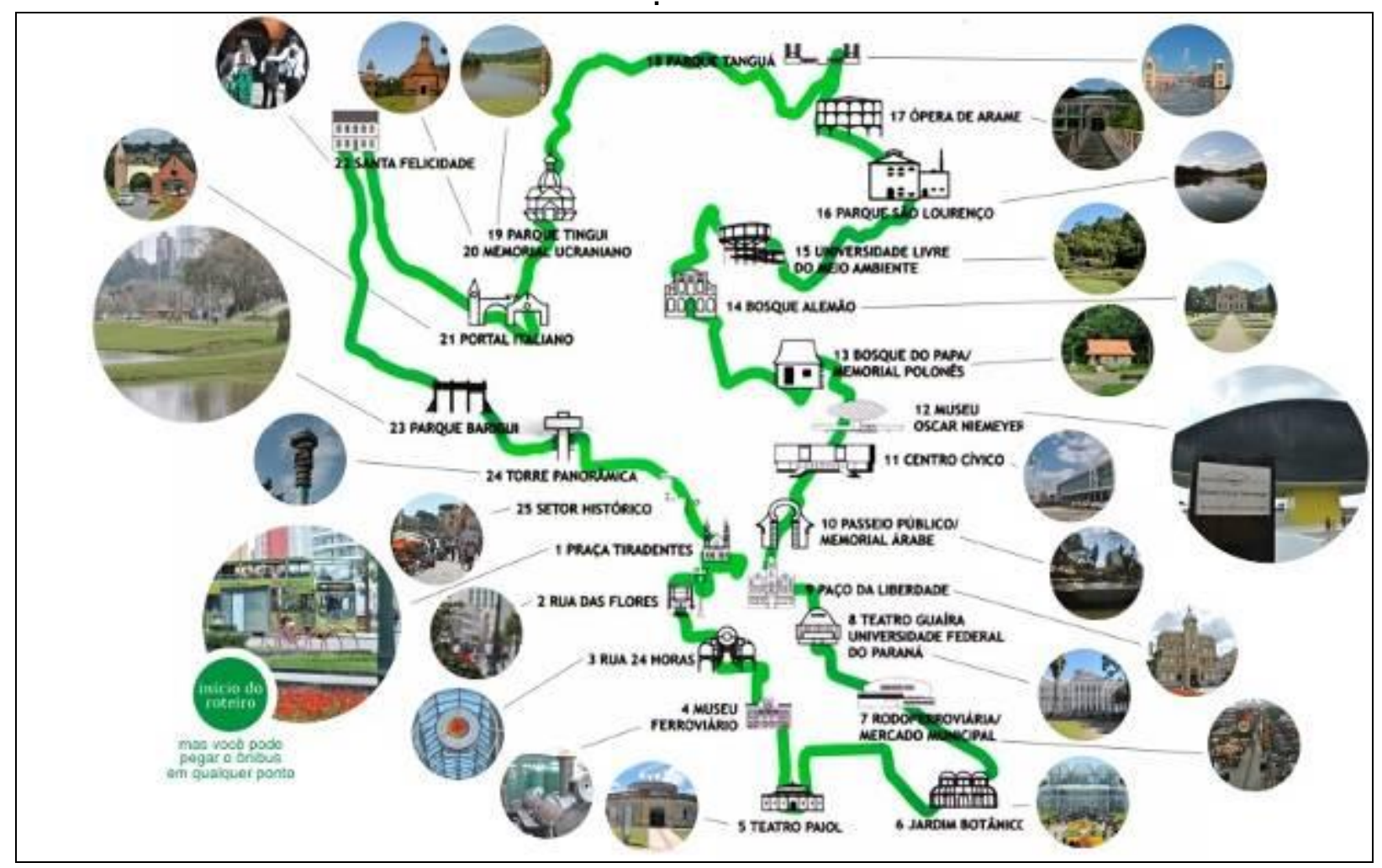

Figura 1: Trajeto Linha Turismo.

Figure 2: Tourism Line route.

Fonte: Curitiba Space (2016).

Source: Curitiba Space (2016). 
O Instituto Municipal de Turismo, em uma pesquisa referente ao ano de 2015 , apontou que $83,8 \%$ dos usuários da Linha Turismo são turistas, $2,6 \%$ são excursionistas, $11,5 \%$ são moradores de Curitiba e 2,1\% são moradores da Região Metropolitana de Curitiba (INSTITUTO MUNICIPAL DE TURISMO, 2015).

Em números absolutos, a Tabela 1 demonstra que a Linha Turismo transportou aproximadamente 660 mil pessoas no ano de 2015, apresentando aumento desse número em relação ao ano de 2013 , no qual transportou aproximadamente 590 mil pessoas (INSTITUTO MUNICIPAL DE TURISMO, 2016).

Tabela 1: Embarque Linha Turismo.

Table 1: Boarding Tourism Line.

\begin{tabular}{lccccc}
$\begin{array}{l}\text { Embarques } \\
\text { Turismo }\end{array}$ & na & Linha & $\mathbf{2 0 1 3}$ & $\mathbf{2 0 1 4}$ & $\mathbf{2 0 1 5}$ \\
\cline { 3 - 5 } & & 591.706 & 659.047 & 657.22 \\
\hline
\end{tabular}

Fonte: Instituto Municipal de Turismo (2016).

Source: Municipal Institute Tourism (2016).

Como objeto de análise ao presente trabalho, adotou-se o conjunto de parques e bosques atendidos por esse serviço: Jardim Botânico, Parque Barigui, Parque Tingui / Memorial Ucraniano, Parque Tanguá, Parque São Lourenço, Bosque Alemão, Bosque do Papa / Memorial Polonês, Passeio Público. Além do atendimento dessas localidades pela Linha Turismo, constata-se que as áreas verdes de Curitiba, os parques e bosques, são atrativos de relevante interesse à visitação na cidade e que a Linha Turismo está entre os produtos mais utilizados para atração dos turistas (RIBEIRO; SILVEIRA, 2006).

Como exemplo ao planejamento urbano relacionado à atividade turística e à diversificação dos usos, o primeiro parque relacionado é o Jardim Botânico, criado em 1991. Ribeiro e Silveira (2006) destacam que a área onde hoje se encontra esse atrativo estava sendo invadida na época de sua criação. Através de ações de planejamento somadas à preservação de parte de sua vegetação, o governo municipal estrategicamente construiu uma área verde para o lazer.

De acordo com o Instituto Municipal de Turismo (2015), pelo $4^{\circ}$ ano consecutivo, o Jardim Botânico foi o atrativo turístico mais visitado pelos usuários da Linha Turismo, com $15,71 \%$ de todos os embarques e desembarques. Conforme destaca Kaick (2007), seu nome oficial é uma homenagem à Urbanista Francisca Maria Garfunkel Rischbieter, uma das pioneiras no trabalho de planejamento urbano de Curitiba.

Com uma área de $178.000 \mathrm{~m}^{2}$, o Jardim Botânico possui legislação própria de utilização pelo decreto $\mathrm{n} \div 471 / 88$. Nesse parque localiza-se 0 Museu Botânico com exposição permanente de exemplares da fauna e flora local. Sua estrutura principal abriga uma estufa de ferro e vidro, com $420 \mathrm{~m}^{2}$, que abriga exemplares da flora característica de regiões tropicais (Figura 2). Além disso, a infraestrutura instalada apresenta lago, pista de caminhada, loja de souvenir, lanchonete e um efetivo sistema de sinalização turística e 
informativo. Entretanto, os jardins são a atração mais significativa do Jardim Botânico, apresentando em seu paisagismo canteiros geométricos que permitem a caminhada por entre eles.

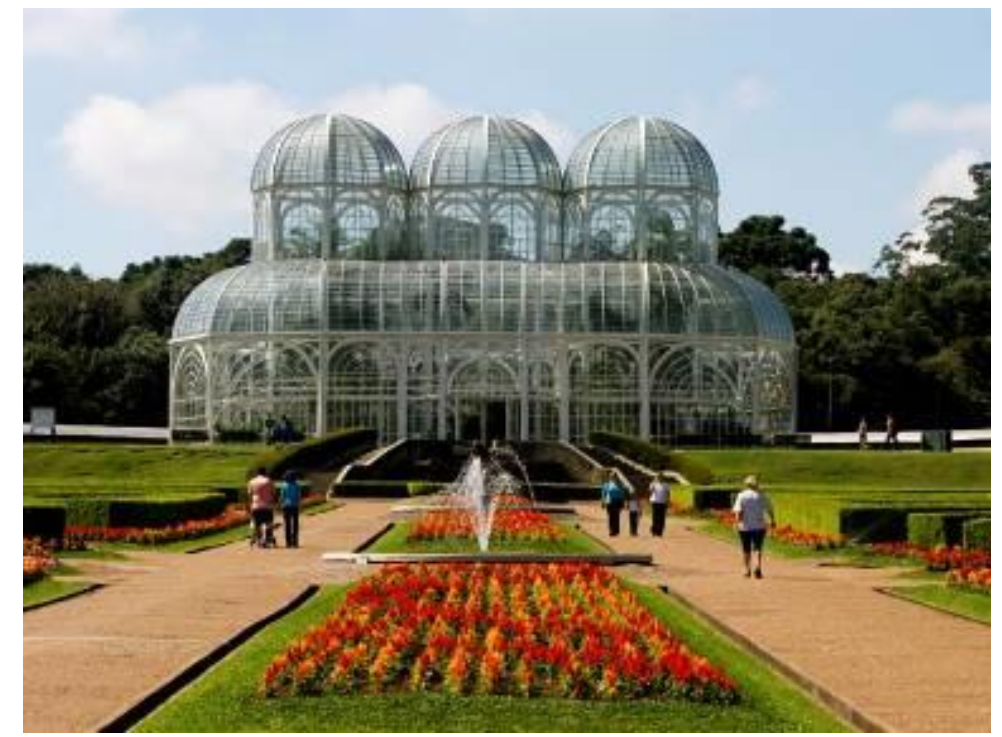

Figura 2: Jardim Botânico.

Figure 2: Botanic Garden.

Fonte: Ministério do Turismo (2016).

Source: Departamento of Tourism (2016).

O Parque Barigui, atendido pela Linha Turismo e contemplado na presente pesquisa foi transformado em parque em 1972 pelo prefeito Jaime Lerner ocupando uma área de antiga sesmaria pertencente a Martins Mateus Leme. Com 1,4 milhão de metros quadrados de área, é um dos maiores parques da cidade e, de acordo com a Prefeitura de Curitiba, devido à proximidade com a região central da cidade e a diversidade de infraestrutura, o Barigui é o parque mais frequentado de Curitiba.

Além da infraestrutura de lazer como pista para caminhadas, quiosques, estacionamento, sanitários, ciclovias, pavilhão de exposições, no Parque Barigui é possível conviver com espécies da fauna como preás, socós, garças brancas, gambás, tico-ticos e sabiás (Figura 3).

Tingui significa "nariz afilado" e é o nome de uma tribo indígena que habitava a região de Curitba na época de sua fundação. O Parque Tingui foi fundado em 1994, possui $380.000 \mathrm{~m}^{2}$ e localiza-se na região norte da cidade. Como exemplo ao planejamento e organização espacial, o Tingui é parte de um projeto de implantação de um parque linear, que unifica os parques Tingui, Tangua e Barigui, todos na extensão do Rio Barigui (Prefeitura de Curitiba). Vale destacar os lagos que são formados pelo Rio Barigui e compõem em torno de $20 \%$ da área total do parque que tem como função, além da composição paisagística, o controle e a redução das cheias do Rio Barigui. Além das opções de lazer proporcionadas pela natureza do parque, no Tingui localiza-se o Memorial Ucraniano, implantado em 1995 (Figura 4). Nele encontra-se uma uma réplica da antiga capela de São Miguel Arcanjo, da Serra do Tigre alem de espaços para eventos e apresentações culturais e serviços turísticos como lojas de produtos típicos. 


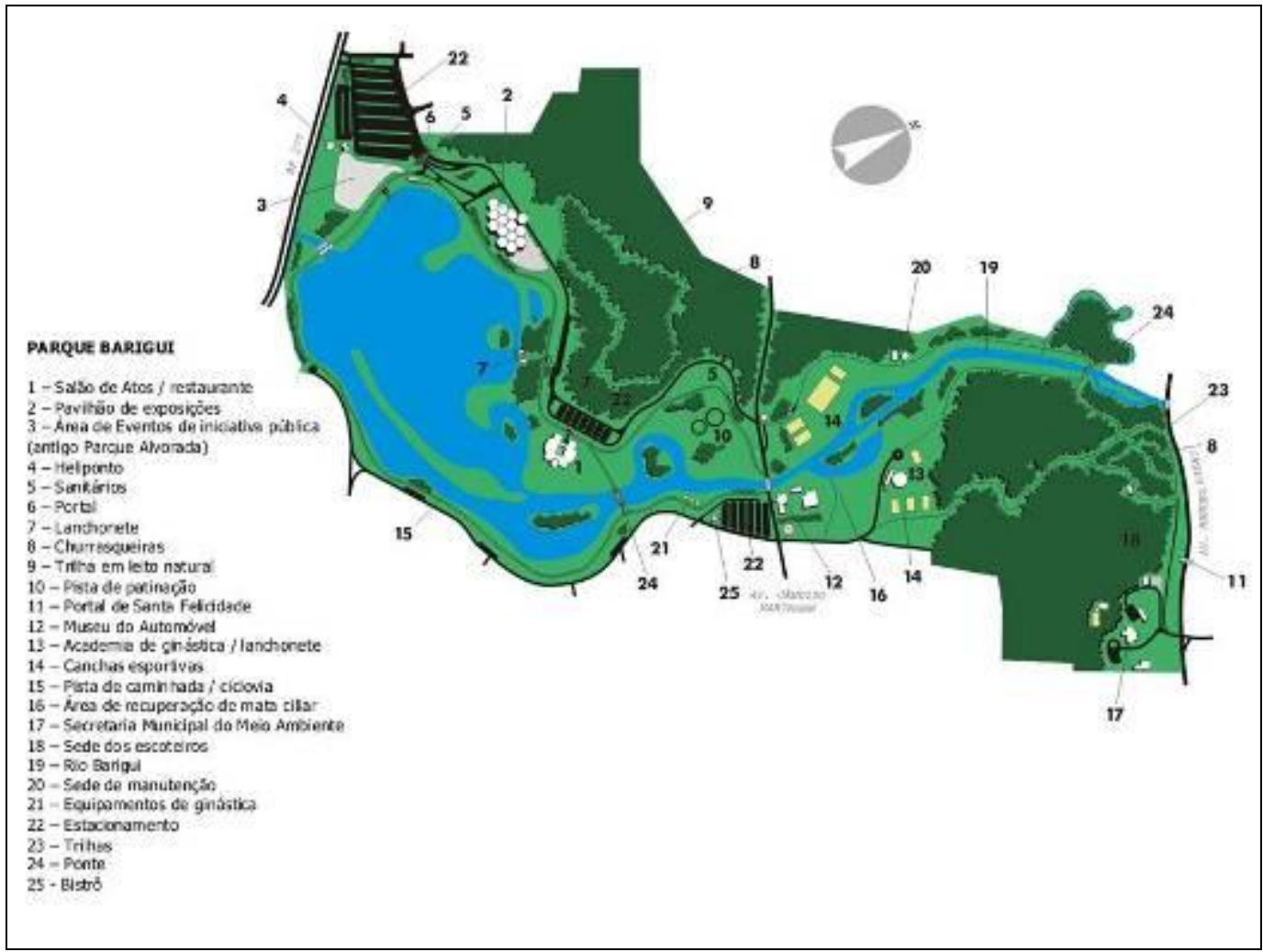

Figura 3: Parque Barigui.

Figure 3: Barigui Park.

Fonte: Secretaria Municipal de Meio Ambiente de Curitiba (2016).

Source: Municipal secretary of environment (2016).

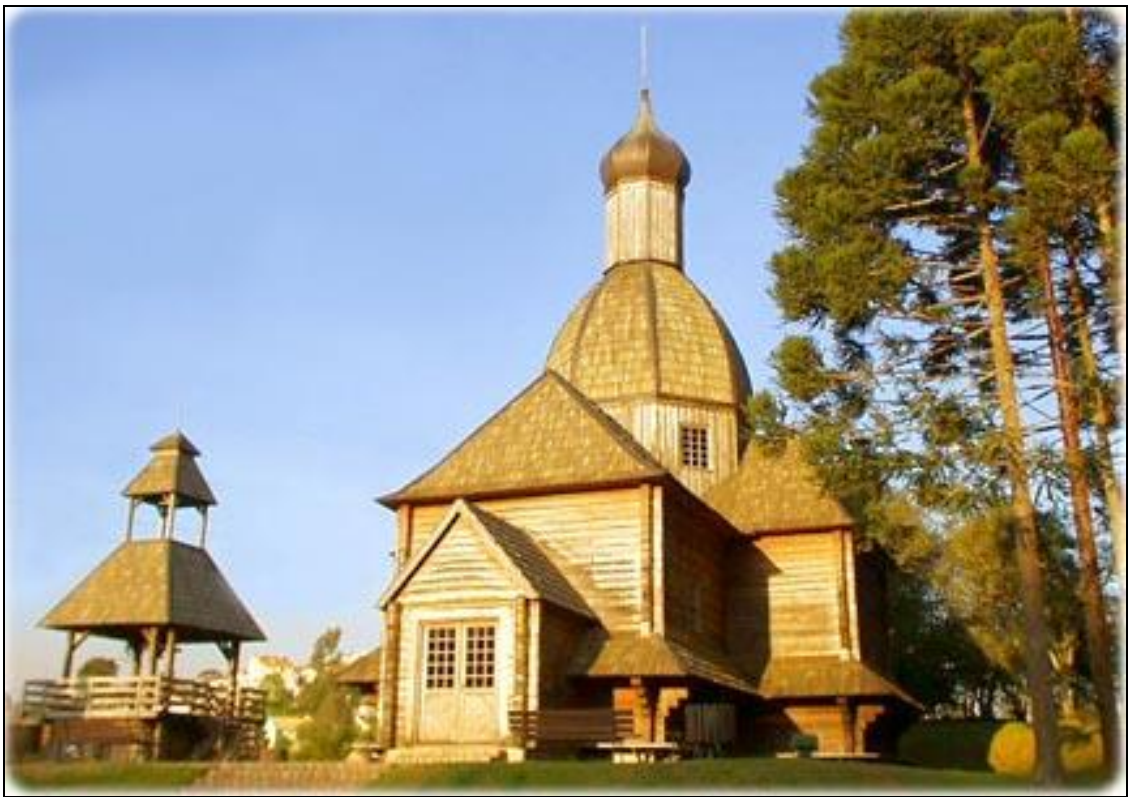

Figura 4: Parque Tingui.

Figura 4: Tingui Park.

Fonte: Secretaria Municipal de Meio Ambiente de Curitiba (2016). Source: Municipal secretary of environment (2016). 
Seguindo o roteiro da Linha Turismo, a parada seguinte é o Parque Tanguá (figura 5). Este parque foi inaugurado em 1996 e possui uma extensão de $235.000 \mathrm{~m}^{2}$ e está situado em uma área de pedreiras desativadas. Antes de ser parque, o local abrigava uma usina de reciclagem de caliça e lixo industrial (SECRETARIA MUNICIPAL DE MEIO AMBIENTE, 2016).

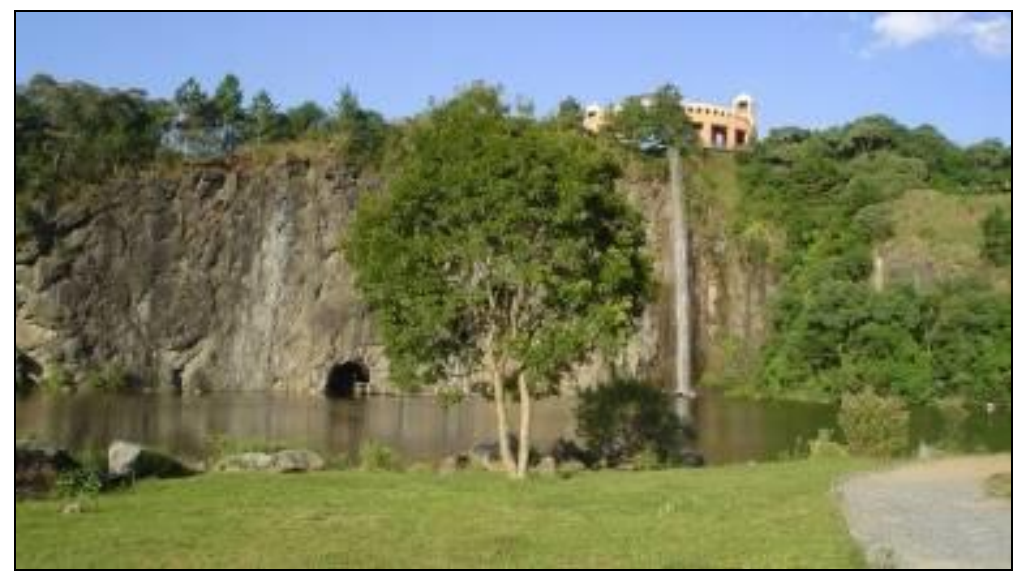

Figura 5: Parque Tanguá.

Figure 5: Tanguá Park.

Fonte: Secretaria Municipal do Meio Ambiente de Curitiba (2016). Source: Municipal secretary of environment (2016).

Hoje, destinado ao turismo e lazer, compondo os principais roteiros de visitação da cidade sendo um dos principais atrativos, o Tanguá diferenciase por possuir um túnel que une dois lagos passando por meio de uma rocha. Passando por esse túnel é possível chegar a um mirante. Há ainda infraestrutura para churrasco e piquenique.

De acordo com o Instituto Municipal de Turismo de Curitiba, em 1998, foi inaugurado o Jardim Poty Lazzarotto, contando com portal de acesso, cascata, canteiros e espelhos d’água, de onde se projeta um mirante de $65 \mathrm{~m}$ de altura. Nos três pavimentos do mirante, distribuem-se torres para observação e locais para os serviços de apoio.

Próximo atrativo, contemplado é o Parque São Lourenço. Como exemplo inicial ao planejamento urbano da cidade, esse parque foi fundado após uma grande inundação em 1970 pelo desenvolvimento de um projeto para a regularização da vazão das águas do Rio Belém e aproveitamento da área ao redor com reciclagem e usina de uma antiga fábrica de cola. Hoje, a antiga fábrica e seu maquinário configuram o "Centro de Criatividade" com exposições, espaço para oficinas e uma biblioteca.

O Bosque Alemão (Figura 6) como o próprio nome sugere, possui diversos equipamentos que homenageiam a cultura alemã, foi fundado em 1996 e localiza-se em uma região de fundo de vale $38.000 \mathrm{~m}^{2}$. Descendo a torre localizada no jardim externo chega-se ao "Caminho dos Contos" percurso no qual expõe em azulejos a história de João e Maria. O "Caminho de João e Maria é um dos principais atrativos desse parque que motiva a visitação principalmente do público infantil. 


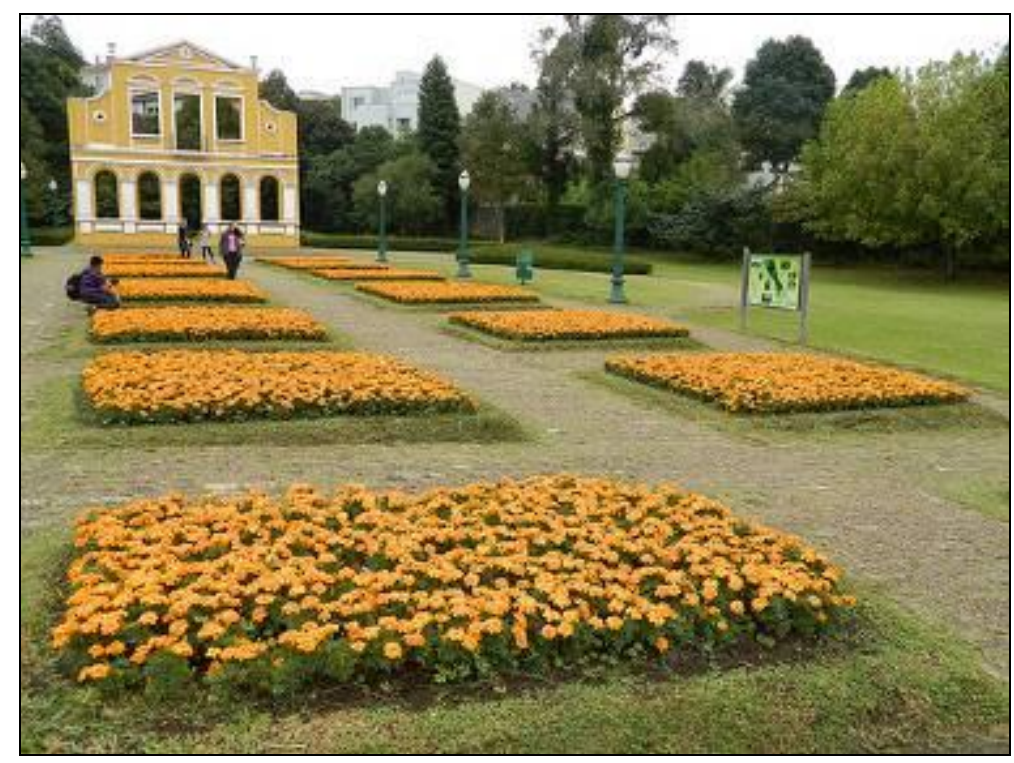

Figura 6: Bosque Alemão.

Figure 6: German Forest.

Fonte: Secretaria Municipal de Meio Ambiente de Curitiba (2016). Source: Municipal secretary of environment (2016).

Com paisagismo de burle Marx, o Bosque do Papa (Figura 7) foi inaugurado logo após a primeira visita do Papa João Paulo II em 1980, possui uma área de $48.000 \mathrm{~m}^{2}$ e é uma homenagem à colônia polonesa. $\mathrm{O}$ Memorial inclui uma capela e exposições de artefatos de madeira utilizados pelos colonos poloneses e artesanato, além das estátuas do Papa João Paulo II e do astrônomo Nicolau Copérnico (PREFEITURA DE CURITIBA, 2016). Representando uma das funções turísticas, o bosque possui loja de artesanato na qual é possível o turista adquirir a tradicional Pêssanka, ovos pintados à mão de tradição Ucraniana.

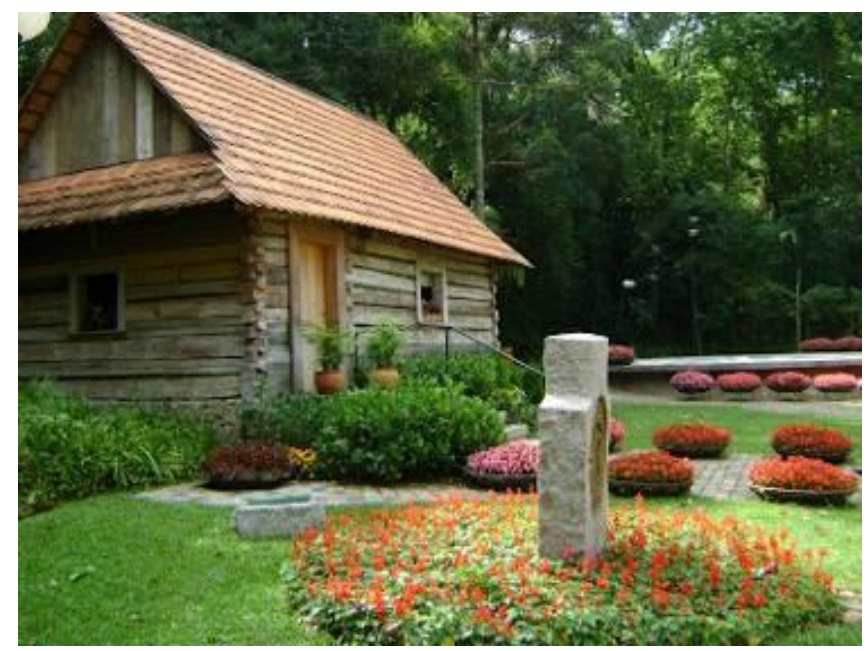

Figura 7: Bosque do Papa

Figure 7: Pope's Forest.

Fonte: Secretaria Municipal de Meio Ambiente de Curitiba (2016). Source: Municipal secretary of environment (2016). 
O roteiro termina no Passeio Público, a mais antiga área verde municipal de Curitiba, com cerca de $70.000 \mathrm{~m}^{2}$. O Passeio Público foi criado por Alfredo D`Estragnolle Taunay e inaugurado em 1886. É o parque mais central da cidade, composto de equipamentos e áreas verdes com diversas espécies nativas e exóticas. A infraestrutura do local pode ser observada na figura 8, a qual demonstra os distintos serviços que hoje atendem à população e ao turista, dentre eles: restaurantes, playground, aquário, terrário, sanitários, ponte pênsil, posto da Polícia Militar, pedalinhos, pista para caminhadas, ciclovia, bicicletário, entre outros.

Um benefício em destaque do Passeio Público é sua apresentação estética favorável para o incentivo ao turismo e também como critério para melhorar a qualidade de vida da população.

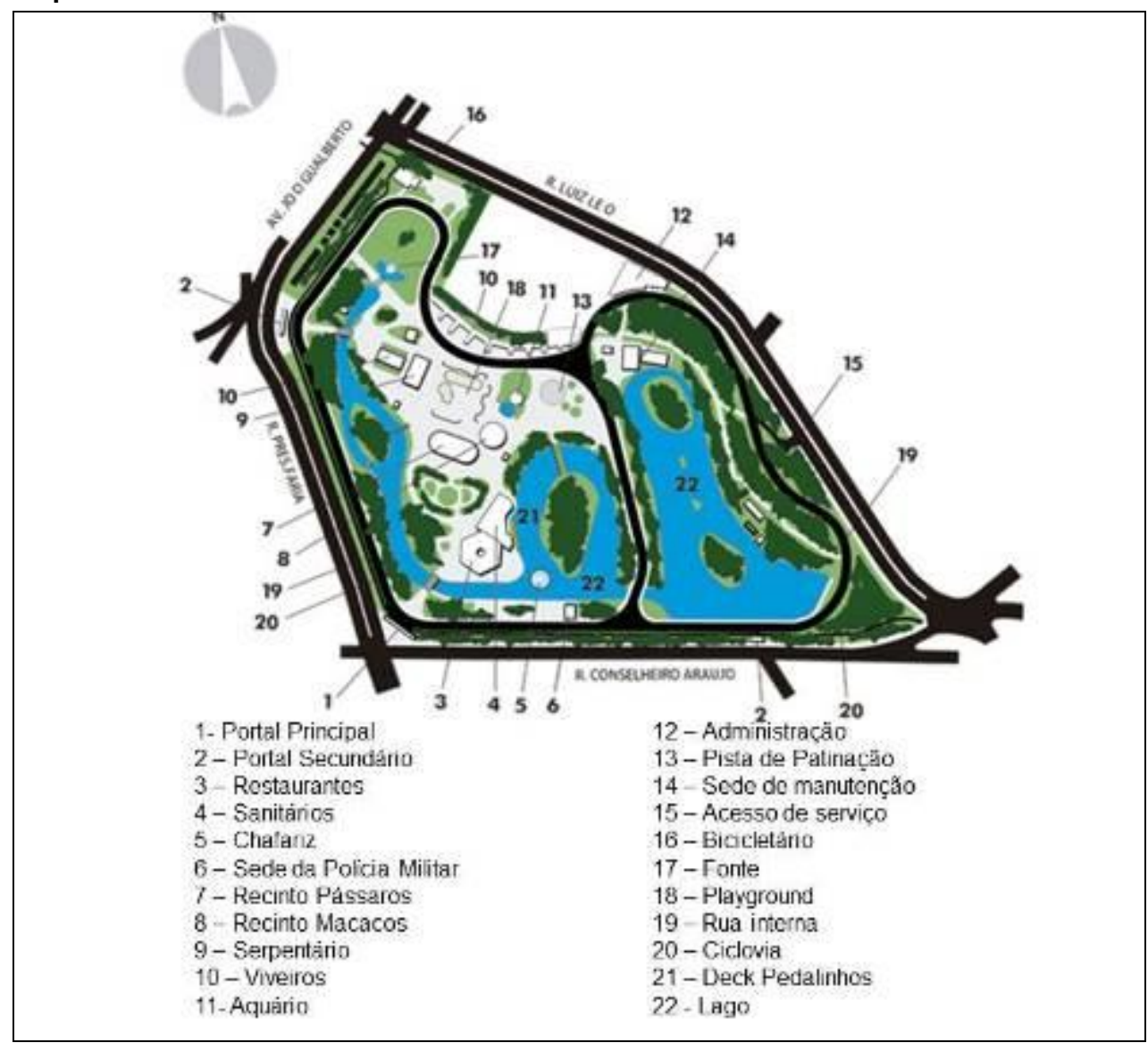

Figura 8: Croqui Passeio Público.

Figure 8: Public Boulevard Scheme.

Fonte: Prefeitura de Curitiba (2016).

Source: City Hall of Curitiba (2016).

O passeio público foi a primeira grande obra de saneamento da cidade, devido à necessidade de drenagem do seu entorno, transformando um charco num espaço de lazer, com lagos, pontes e ilhas em meio ao verde (INSTITUTO MUNICIPAL DE TURISMO, 2016). Atualmente, no Passeio Público encontra-se a sede do Departamento de Proteção e Conservação da Fauna e abriga os pequenos animais que permaneceram quando o Zoológico foi transferido para o Parque Iguaçu em 1982. 
É evidente, a partir do conhecimento dos atrativos da Linha de Turismo de Curitiba, que as áreas verdes se destacam e, além da funcionalidade como atrativo, estas áreas estão inseridas nas políticas de organização do espaço urbano, ao servirem principalmente como espaços de lazer e bem-estar social à população.

\section{Considerações finais}

Conforme foi apresentado, o objetivo principal do presente trabalho foi qualificar os principais parques urbanos de Curitiba apresentados como atrativos turísticos, entendendo que essa disposição espacial somada a oferta de serviços e infraestrutura potencializam sua atratividade para a atividade turística. Para isso, adotou-se a Linha Turismo como elo para a interação entre o planejamento urbano e o planejamento do turismo.

A presença e uso dos espaços verdes para a prática do lazer e do turismo está relacionada aos desejos e costumes da população urbana atual, em busca de qualidade de vida ao estar em contato com a natureza.

Foi possível demonstrar que a lógica de organização da cidade está cada vez mais relacionada à lógica da atividade turística e que, é interesse de ambas a integração e a socialização de interesses. O planejamento da cidade ocorrendo de maneira articulada ao planejamento do turismo é a condição para a ocorrência de um turismo atrativo e competitivo para a localidade. Além disso, as duas práticas ocorrendo de maneira articulada, podem beneficiar o desenvolvimento local, influenciando na qualidade de vida da população local e, consequentemente, beneficiando a atividade turística.

O exemplo da Linha Turismo pretendeu demonstrar que uma intervenção no setor de transportes, facilitando e incentivando o deslocamento entre os principais parques da cidade (sem contar os demais locais não abordados pelo presente trabalho), atrai e estimula não só a visitação, como incentiva melhorias de infraestrutura e manutenção dos locais, como iluminação, sanitários, áreas de lazer e alimentação.

Pela qualificação dos atrativos abordados, foi possível perceber que a presença de estruturas físicas para a prática do lazer e de elementos de embelezamento são incentivadores do turismo e critério para melhorar a qualidade de vida da população.

Os resultados dessa troca de benefícios podem ser de uso tanto do morador como do turista, caracterizando um ciclo de usos e melhorias para a cidade, seus moradores e turistas.

Em síntese, a cidade de Curitiba elaborou o planejamento urbano com preservação de espaços públicos para beneficiar diretamente os residentes e, como consequência, destinam-se como atrativos para a prática do turismo. Dencker (1998) afirma que antes da localidade elaborar seu planejamento para o turismo, deve-se elaborar políticas urbanas para conceber qualidade de vida aos moradores, ou seja, a cidade estará preparada para receber turistas apenas quando oferecer parâmetros de bem-estar para à população local. 


\section{Referências}

ANJOS, F.A. Processo de Planejamento e Gestão de territórios turísticos: uma proposta sistêmica. 2004. 245 f. Tese - (Doutorado em Engenharia de Produção) - Programa de Pós-Graduação em Engenharia de Produção, Universidade Federal de Santa Catarina, Florianópolis.

BACAL, S. Lazer e o Universo dos possíveis. São Paulo: Aleph, 2003.

BENI, M. C. Análise estrutural do turismo. 10ª ed. São Paulo: SENAC São Paulo, 2004.

BOULLON, R.C. Planejamento do espaço turístico. Bauru, SP: EDUSC, 2002.

BOULLÓN, R.; MOLINA, S.; WOOG, M.R. Um novo tempo livre. São Paulo: EDUSC, 2004.

CAMARGO, L.H. Fundamentos multidisciplinares do turismo: história. In: TRIGO, L. G. G. (Org.). Turismo: como aprender, como ensinar. São Paulo: SENAC, 2000. p. $23-32$.

CASTELNOU, A.M.N. Parques urbanos de Curitiba: de espaços de lazer a objetos de consumo. Cadernos de Arquitetura e Urbanismo, Belo Horizonte, v. 13, n¹4, 2006, p.53-73.

CASTROGIOVANNI, A.C. Turismo urbano. São Paulo: Contexto, 2001. p. 11-22.

CAVALCANTI, E; NEVES, M. F. O turismo urbano. Disponível em: <http://www.fotoserumos.com/curitibaviavel4.htm>. Acesso em: 23 jun. 2016.

CIDADE, L.C.F; PELUSO, M.L. Urbis e Civitas em Brasília: um diálogo impossível. Espaço \& Geografia, Brasília, v. 5, n², 2002. p.191-222.

COSTA, C. An Emerging Tourism Planning Paradigm? A comparative analysis between town and tourism planning. Internacional Journal of Tourism Research. V.3, 2001, p. $425-441$.

CURITIBA. Secretaria Municipal do Meio Ambiente. Bosque do Papa. Disponível em: http://www.curitiba.pr.gov.br/conteudo/parques-e-bosquesbosque-j-paulo-ii/277. Acesso em: 20 de junho de 2016.

DENCKER, A.F.M. Pesquisa em turismo: planejamento, métodos e técnicas. São Paulo: Futura, 1998.

FERRARI JUNIOR, J. C. Limites e potencialidades do planejamento urbano: uma discussão sobre os pilares e aspectos recentes da organização espacial das cidades brasileiras. Estudos Geográficos, Rio Claro, v. 2, n¹, 2004, p. $15-28$.

GANDARA, J.M; RAMOS, S.C.; TRAMONTIM, R. Turismo e Planejamento urbano: uma análise sobre o caso de Curitiba. Anais. V Seminário da Associação Nacional de Pesquisa e Pós Graduação em Turismo. Belo Horizonte, 2008.

GIL, A.C. Como elaborar projetos de pesquisa. $4^{\underline{a}}$ ed. São Paulo: Atlas, 2009. 
INSTITUTO MUNICIPAL DE TURISMO. Pesquisa de perfil, comportamento e opinião linha turismo - Curitiba, 2015.

INSTITUTO MUNICIPAL DE TURISMO. Disponível em: <http://www.turismo.curitiba.pr.gov.br/>. Acesso em: 10 ago. de 2016.

LAKATOS, E.M.; MARCONI, M.A. Fundamentos de metodologia científica. $7^{\mathfrak{a}}$ ed. São Paulo: Atlas, 2010.

LIMA, A. M. et al. Problemas de utilização na conceituação de termos como espaços livres, áreas verdes e correlatos. In: Anais do Congresso Brasileiro de Arborização Urbana. São Luís, 1994.

MARCELLINO, N.C. Estudos do lazer: uma introdução. Campinas: Autores Associados, 2000.

MARCELLINO, N.C. Lazer e Humanização. Campinas: Papirus, 1983.

MICHEL, M.H. Metodologia e pesquisa científica em ciências sociais: um guia prático para acompanhamento da disciplina e elaboração de trabalhos monográficos. São Paulo: Atlas, 2005.

MOLINA, S. Turismo: metodologia para su planificación. México: Trilhas, 1997.

KAICK, J. A. M. Percepção de parques e áreas similares para a atratividade do turismo em Curitiba, Paraná. 2007. 158f. Dissertação - (Mestrado em Gestão Urbana) - Pontifícia Universidade Católica do Paraná, Curitiba.

PREFEITURA DE CURITIBA. Disponível em:< http://www.curitiba.pr.gov.br/>. Acesso em: 18 ago de 2016.

PORTUGUEZ, A.P. Consumo e Espaço: turismo, lazer e outros temas. São Paulo: Roca, 2001.

REIS, C.M. Brasília: espaço, patrimônio e gestão urbana. 2001. 156 f. Dissertação - (Mestrado em Arquitetura e Urbanismo) - Universidade de Brasília, Brasília.

RIBEIRO, R.M.; SILVEIRA, M.A.T. Planejamento Urbano, Lazer e Turismo: os parques públicos em Curitiba - PR. Turismo Visão \& Ação, v. 8, n², 2006, p. $309-321$.

RODRIGUES, A.B. Turismo e Espaço: rumo a um conhecimento transdisciplinar. São Paulo: Hucitec, 2001.

SECRETARIA MUNICIPAL DE MEIO AMBIENTE. Parque Tanguá. Disponível em: http://www.curitiba.pr.gov.br/conteudo/parques-e-bosquesparque-tangua/318. Acesso em: 20 ago. de 2016.

SESSA, A. Turismo e política de desenvolvimento. Porto Alegre. Uniontur, 1983.

SILVA, M.G.L. Cidades Turísticas: identidades e cenários de lazer. São Paulo: Aleph, 2004.

URBS - URBANIZAÇÃO DE CURITIBA. Linha turismo. Disponível em: https://www.urbs.curitiba.pr.gov.br/transporte/linha-turismo. Acesso em: 23 ago de 2016. 
YÁZIGI, Eduardo. Sedução da cidade para nós e o turismo. In: TRIGO, L. G. (Org.) Análises regionais e globais do turismo brasileiro. $1^{\underline{a}}$ ed. São Paulo: Roca, 2005, p. 71-79.

WAINBERG, J. Cidades como sites de excitação turística. In: CASTROGIOVANNI, A.C. (Org.). Turismo urbano. São Paulo: Contexto, 2000

Fabiana Calçada de Lamare Leite: Instituto Federal de Santa Catarina, Florianópolis, SC, Brasil.

E-mail: fabianadelamare@yahoo.com.br

Link para o currículo Lattes: http://lattes.cnpq.br/8124487431483803

Aline Patrícia Henz: Universidade Estadual do Oeste do Paraná, Foz do Iguaçu, PR, Brasil.

E-mail: alinepatriciah@yahoo.com.br

Link para o currículo Lattes: http://lattes.cnpq.br/7617252840194323

Data de submissão: 29 de agosto de 2016

Data de recebimento de correções: 05 de setembro de 2017

Data do aceite: 05 de setembro de 2017

Avaliado anonimamente 